\title{
miR-182-5p Inhibition Ameliorates Ischemic Acute Kidney Injury
}

Julia Wilflingseder, ${ }^{*}$ Kíra Jelencsics, ${ }^{*}$ Helga Bergmeister, ${ }^{\dagger}$ Judith Sunzenauer, ${ }^{*}$ Heinz Regele, ${ }^{\ddagger}$ Farsad Eskandary, ${ }^{*}$ Roman Reindl-Schwaighofer, ${ }^{*}$ Alexander Kainz, ${ }^{*}$ and Rainer Oberbauer*

From the Departments of Nephrology and Dialysis, ${ }^{*}$ Biomedical Research, ${ }^{\dagger}$ and Pathology, ${ }^{\ddagger}$ Medical University Vienna, Vienna, Austria

\author{
Accepted for publication \\ September 12, 2016. \\ Address correspondence to \\ Rainer Oberbauer, M.D., \\ Department of Nephrology \\ and Dialysis, Medical Univer- \\ sity of Vienna, Währinger \\ Gürtel 18-20, 1090 Vienna, \\ Austria. E-mail: rainer. \\ oberbauer@meduniwien.ac.at.
}

\begin{abstract}
Acute kidney injury (AKI) remains a major clinical event with high mortality rates. We previously identified renal miR-182 as the main driver of post-transplantation AKI. Therefore, we tested the causal inference of miR-182 by inhibiting its renal expression in vivo. In 45 rats AKI was induced by right nephrectomy and contralateral clamping of the renal pedicle for 40 minutes. Systemically administered antisense oligonucleotide (ASO) inhibited miR-182 in the kidneys up to 96 hours. The maximum creatinine elevation was on day 2 after injury ( $\mathrm{mg} / \mathrm{dL}$; median and interquartile range): ASO 2.5mg/kg: 1.9 $(1.3 ; 3.2)$, ASO 25mg/kg: $2.8(0.7 ; 5.0)$, mismatch oligonucleotide (MM) $25 \mathrm{mg} / \mathrm{kg}: 5.7(5,0 ; 5.8)$, saline: $4.4(3.5 ; 5.8)(P=0.016$, analysis of variance $)$. Blinded semiquantitative histologic evaluation of renal biopsies showed better preserved morphology in both ASO groups than saline- and MM-treated kidneys (median and interquartile range of overall injury scores): ASO both concentrations $1(1,1)$, saline $3(3,3)$ and MM $3(3,3)(P<0.001$, analysis of variance). ASO facilitated cell proliferation, metabolism, and angiogenesis on a genome-wide level. ASO when applied in normothermic kidney machine perfusion reduced renal miR-182 expression by more than two magnitudes. In summary, we showed that in vivo inhibition of miR-182 by ASO improved kidney function and morphology after AKI. This technique may be applicable to reduce the high rate of AKI in the human renal transplantation setting. (Am J Pathol 2017, 187: 70-79; http://dx.doi.org/10.1016/j.ajpath.2016.09.011)
\end{abstract}

Acute kidney injury (AKI) is highly prevalent in patients in the intensive care unit but also in renal allograft recipients, and it causes high mortality rates and reduced allograft survival, respectively. ${ }^{1}$

We showed previously that inflammation in the donor kidney before engraftment is highly associated with elevated rates of AKI after transplantation. ${ }^{2}$ However, inflammation may not be the only driver of this process because inhibition of inflammation on a genome-wide level by steroid pretreatment of donors before organ harvesting did not reduce the incidence of AKI in human kidney transplantation. ${ }^{3}$ Other pathways such as cell-cycle regulation, proliferation, and transcription factors play a crucial part but may not be affected by systemic administration of steroids. ${ }^{4}$

Transcriptomics experiments in human donor kidneys showed that these pathways were associated with AKI and that several of these entities are regulated by a few miRNAs. ${ }^{5}$ miRNAs are a class of small noncoding, 18 to 24 nucleotide- long RNAs that have been implicated recently in diverse cellular functions. miRNAs regulate their target genes posttranscriptionally via mRNA degradation and/or inhibition of translation. ${ }^{6}$ One miRNA can potentially target a wide variety of proteins, frequently in the context of a network, making them extremely efficient in regulating distinct cellular processes relevant to specific clinical phenotypes. This feature is one of the most appealing properties of miRNAs as therapeutic agents and is probably the most important advantage in comparison with approaches targeting single genes. They have been used successfully to treat indolent diseases such as drug-refractory hepatitis $\mathrm{C}$ virus infection in humans. ${ }^{7}$

\footnotetext{
Supported by a Marie Curie International Outgoing Fellowship within the 7th European Community Framework Program grant 328613 (J.W.) and the Austrian Science Fund grant P25726 (J.W. and K.J.).

J.W. and K.J. contributed equally to this work.

Disclosure: None declared.
} 
We recently identified a specific miRNA signature discriminating post-transplantation AKI from primary graft function and in subsequent studies identified miR-182-5p as the main driver of AKI. ${ }^{8}$ Verified target genes of miR-182$5 \mathrm{p}$ are involved in apoptosis, cell-cycle, T-cell differentiation, proliferation, and migration pathways to balance cell death and repair as well as regeneration processes of the kidney. ${ }^{2,9,10}$ To test for causality, specific antisense oligonucleotides (ASOs) against miR-182-5p were investigated in an animal model of AKI.

\section{Material and Methods}

\section{ASO and MM Generation}

Both oligonucleotides were produced by Exiqon (Vedbaek, Denmark); both are 15 mer long and had a fully phosphorothioate-modified backbone. Mismatch oligonucleotide (MM) is identical to ASO except for 4-bp changes that prevent binding to miR-182-5p. Both oligonucleotides were purified by reverse-phase high-performance liquid chromatography and lyophilized. Because human, mouse, rats, and pigs share sequence homology over the full 15-mer binding site of the designed ASO, all four species can be targeted with it.

\section{HK2 Cell Culture, ASO, and MM Transfection}

Human renal proximal tubular epithelial (HK2) cells were cultured in keratinocyte serum-free medium with L-glutamine, bovine pituitary extract $(25 \mu \mathrm{g} / 500 \mathrm{~mL}), 2.5 \mu \mathrm{g} / 500 \mathrm{~mL}$ human recombinant epidermal growth factor 1 to 53 (Life Technologies, Carlsbad, CA), $10 \%$ of heat-inactivated fetal bovine serum, and 1\% penicillin/streptomycin (both Sigma-Aldrich, St. Louis, MO). ASO or MM was introduced into HK2 cells at a final concentration of 250,25 , and $2.5 \mathrm{pmol} / \mathrm{L}$. HK2 cells were plated in 6-well plates and transfected 24 hours later using Lipofectamine RNAiMAX (Invitrogen, Waltham, MA).

\section{Animal Experiments}

Time and concentration kinetics studies of oligonucleotides were performed in healthy mice for cost reasons. ASO and MM were resuspended under sterile conditions in RNase-free water to a final concentration of $100 \mu \mathrm{g} / \mu \mathrm{L}$. A dose of $25 \mathrm{mg} /$ $\mathrm{kg}$ (of ASO and MM) or $2.5 \mathrm{mg} / \mathrm{kg}$ (of ASO) body weight oligonucleotide in a total volume of $500 \mu \mathrm{L} \mathrm{NaCl} 0.9 \%$ or saline alone was injected via the tail vein into 8- to 12-weekold male C57BL/6 mice (Charles River, Burlington, MA).

Power analysis of the rat AKI study was based on the following assumptions: a SD of 0.65 of day 2 creatinine measurements after the ischemic injury was assumed according to the study of Oberbauer et al. ${ }^{11}$ A sample size of 10 rats is needed to detect a mean difference of $1 \mathrm{mg} / \mathrm{dL}$ for the creatinine values between the ASO treatment and the control group with a power of 0.8 and a significance level of
0.05. In case of lost to follow-up (death) all previous observed creatinine values were included in the analysis.

Thus, 45 randomly assigned male Sprague-Dawley ${ }^{12}$ rats weighing 305 to $410 \mathrm{~g}$ were treated with ASO $(n=15$ at 2.5 $\mathrm{mg} / \mathrm{kg}$ or $n=10$ at $25 \mathrm{mg} / \mathrm{kg})$, saline $(n=15$ at $\mathrm{NaCl} 0.9 \%)$, or MM ( $n=5$ at $25 \mathrm{mg} / \mathrm{kg}) 24$ hours before the ischemic insult. Anesthesia was introduced with isoflurane. Then the rats were orotracheally intubated and ventilated volumecontrolled (40\% oxygen, 3\% isoflurane). Piritramide (4.5 $\mathrm{mg} / \mathrm{kg}$; JANSSEN-CILAG, Beerse, Belgium) was administered as pain relief agent. The animals were placed on a temperature-regulated table, received a rectal thermo probe, and were kept at $36.5^{\circ} \mathrm{C}$ during 40 minutes of cross clamping of the left renal artery and vein, followed by right-sided nephrectomy (Supplemental Figure S1). Blood (200 $\mu \mathrm{L})$ was drawn each day (day 0 to 7 ) by a catheter system from all animals for the measurement of serum creatinine (with the standardized modified Jaffè method), blood urea nitrogen, sodium, and potassium. The body weight was monitored daily. On day 7 animals were euthanized. The remaining left kidneys were harvested and cut longitudinally into two pieces. One half was further divided for RNA and protein extraction as well as for formalin fixation. The other half was snap-frozen and stored at $-80^{\circ} \mathrm{C}$. In addition, three rats in the ASO and saline groups were prepared and euthanized on day 2 for renal gene expression and morphologic studies.

All procedures involving mice and rats were approved by the Ethics Committee for Laboratory Animal Research of the Medical University Vienna and by the Advisory Committee for Animal Experiments of the Austrian Ministry of Science (Bundesministerium für Wissenschaft und Forschung; file nos. 66.009/0223-II/3b/2012 and 66.009/0009II/3b/2014).

\section{RNA Extraction and Real-Time Quantitative PCR}

Total RNA was isolated and purified from the rat and pig kidney using chloroform and TRIzol reagent (Invitrogen, Carlsbad, CA). To quantify miRNA expression, the TaqMan MicroRNA Reverse Transcription Kit with RNase Inhibitor was used to synthesize single-stranded cDNA. Real-time PCR was performed using the TaqMan miRNA expression assays with the ABI 7300 Real-Time PCR System. All instruments and reagents were purchased from Life Technologies. Relative gene expression values were evaluated with the $2^{-\Delta \Delta \mathrm{Ct}}$ method using U6 snRNA as control small RNA and Stratagene Universal human reference RNA (Stratagene, La Jolla, CA) as reference RNA. miR-146b was used as control because it is not regulated in AKI according to our studies. ${ }^{8}$

The High Capacity cDNA Reverse Transcription Kit with RNase Inhibitor (Thermo Fischer Scientific, Waltham, MA) was used to quantify expression of miR-182-5p targets in the pig kidney. The targets were selected based on the results of the microarray analysis. Real-time PCR was performed using the SYBR Green Universal Master Mix 
(Thermo Fischer Scientific). Relative gene expression values were evaluated with the $2^{-\Delta \Delta \mathrm{Ct}}$ method using $G A P D H$ as reference.

Real-time quantitative PCR conditions were set according to the manufacturer's recommendations: 10 minutes at $95^{\circ} \mathrm{C}, 40$ cycles $\left(15\right.$ seconds at $95^{\circ} \mathrm{C}, 1$ minute at $\left.60^{\circ} \mathrm{C}\right)$ with fluorescence reading during annealing step using the $\mathrm{ABI}$ 7300 Real-Time PCR System. The primer sequences can be found in Table 1.

\section{Histology}

Histologic evaluation was performed on $2-\mu \mathrm{m}$ sections of formalin-fixed, paraffin-embedded kidney tissue stained with hematoxylin and eosin and periodic acid-Schiff by a pathologist blinded for treatment assignment (H.R.) according to the Banff07 donor kidney classification. ${ }^{13}$ Morphologic indicators of acute tubular injury (tubular ectasia, protein casts, luminal debris, vacuolization, and necrosis of tubular epithelial cells), tubular calcification, signs of epithelial cell regeneration, interstitial inflammation, and interstitial fibrosis were recorded semiquantitatively by a pathologist (H.R.) on a 0 to 3 scale. These parameters were used for estimating the overall severity of kidney damage expressed as overall injury score (0 to 3). A Nikon (Tokyo, Japan) Eclipse 80i microscope was used with a DS-2Mv camera (NIS Elements software version 4.0; Nikon).

\section{Microarray Analysis}

For mRNA whole-genome gene expression analysis, we used $200 \mathrm{ng}$ of total RNA of three saline-treated rats and

Table 1 Primer Sequences of miR-182-5p Targets

\begin{tabular}{ll}
\hline Target & Sequence \\
\hline Fam129a & \\
Forward primer & $5^{\prime}$-GAAATCGGACCCTGACCCAG-3' \\
Reverse primer & $5^{\prime}$-CTTCCAAGAGACACGCACGA-3' \\
Kcnj10 & \\
Forward primer & $5^{\prime}$-GGCTATGGCTTCCGCTACAT-3' \\
Reverse primer & $5^{\prime}$-GCTGGGCAATAAGAAGCACG-3' \\
TEK & \\
Forward primer & $5^{\prime}$-GGCTATGGCTTCCGCTACAT-3' \\
Reverse primer & $5^{\prime}$-GCTGGGCAATAAGAAGCACG-3' \\
Dpt & \\
Forward primer & $5^{\prime}$-GTGGCTGTGAGGAGCATCTT-3' \\
Reverse primer & $5^{\prime}$-GGCGTAGTTCCACTGTCTGT-3' \\
Ppp1r1a & \\
Forward primer & $5^{\prime}$-ACTGGGAAAGCAGACAAGCC-3' \\
Reverse primer & $5^{\prime}$-TGTGCTCGGTTTCTCACTGC-3' \\
$\beta$-Actin & \\
Forward primer & \\
Reverse primer & $5^{\prime}$-AGGCCAACCGTGAGAAGATG-3' \\
GAPDH & $5^{\prime}$-GGCGTGTTGAAGGTCTCGAA-3' \\
Forward primer & \\
Reverse primer & $5^{\prime}$-CCACTTTTGATGCTGGGGCT-3' \\
\hline
\end{tabular}

three rats treated with $2.5 \mathrm{mg} / \mathrm{kg}$ ASO before clamping. Amplification and labeling were performed with Applause WT-Amp Plus ST Kit and Encore Biotin Module Kit (NuGEN, San Carlos, CA), followed by hybridization to Affymetrix GeneChip Rat Gene 2.0 ST arrays (Affymetrix, Santa Clara, CA). Affymetrix data were pre-processed, normalized, and summarized using the robust multiaverage method with quantile normalization and were annotated using the corresponding annotation file (.cdf) in Bioconductor. Microarray raw data files are available in the Gene Expression Omnibus (http://www.ncbi.nlm.nih.gov/ geo; accession number GSE69803). Intensity filtering was used to exclude features with low signal intensity $\left(\log _{2}\right.$ level <4.5) over all profiles. ${ }^{14}$ Significance analysis of microarrays using a minimum fold change of 1.3 and a false discovery rate of $10 \%$ were followed to identify differentially regulated mRNAs between the groups. ${ }^{15}$ The number of the binding sites for miR-182 was determined by three independent prediction algorithms (DIANAmT, ${ }^{16,17}$ miRanda, ${ }^{18}$ and Targetscan ${ }^{19}$ ).

\section{ELISAs}

The enzyme-linked immunosorbent assays (ELISAs) were ordered as kits, targeting the specific proteins, and all were performed according to the manufacturer's protocol (MyBioSource, Inc., San Diego, CA). Verified targets of the miR-182 ( $n=3$ at day 2 and $n=5$ at day 7 ) with strong evidence were chosen from the miRTaRBase [http:// mirtarbase.mbc.nctu.edu.tw; cylindromatosis (CYLD): MIRT006978; cyclin D2 (CCND2): MIRT007064]. ${ }^{20}$

\section{Ex Vivo Machine Perfusion System}

Immediately after the harvest of the pig kidney the renal artery and vein were cannulated, and the kidney was flushed with $1 \mathrm{~L}$ of ice-cold custodiol histidine-tryptophan-ketoglutarate (HTK) solution (Essential Pharmaceuticals, Ewing, $\mathrm{NJ})$. During the transport the kidneys were placed on ice for approximately 1 hour. Then the kidney was flushed again with custodiol and connected to the perfusion machine. This was designed using a blood pump with speed controller (Stöckert, Freiburg, Germany), a heat exchanger (Stöckert), a 5-L venous reservoir (Medtronic Autolog, Minneapolis, MN), an oxygenator (Maquet Quadrox-i Pediatric, Rastatt, Germany), and a flow probe (Transonic, Ithaca, NY). The perfusate (University of Wisconsin solution; Bridge to Life, Columbia, SC) was $16^{\circ} \mathrm{C}$ cold and gradually heated up to $34^{\circ} \mathrm{C}$ and oxygenated with $95 \% \mathrm{O}_{2} / 5 \% \mathrm{CO}_{2}$ at $0.5 \mathrm{~L} / \mathrm{min}$. The circuit was primed with University of Wisconsin solution with a total circulating volume of approximately 1000 $\mathrm{mL}$. The filtrate produced by the kidney during perfusion was re-filled into the venous reservoir. The renal blood flow, mean arterial pressure, and urine output were measured and recorded continuously. 
Kidneys were perfused at a mean arterial pressure of 75 to $90 \mathrm{mmHg}$ with a maximum flow of $0.188 \mathrm{~L} / \mathrm{min}$. After 30 minutes of perfusion $25 \mathrm{mg}$ of ASO diluted in $5 \mathrm{~mL}$ of Ringer solution was administered into the arterial arm of the circuit and circulated for 6 hours. Biopsies were taken every 2 hours. The kidney looked evenly perfused. A picture of the system and the cannulated kidney can be found in the Supplemental Figure S2.

\section{Statistical Analysis}

The miR-182-5p expression levels were analyzed by $t$-test against baseline. We used analysis of variance to compare the creatinine values on day 2 of all groups and to compare values from the histologic evaluation for overall injury, and we used $U$-test to compare each group in every evaluation criteria. For post hoc analysis between the groups we used the Dunnett correction with the control groups saline and MM. The ELISA results were tested by $U$-test or $t$-test when appropriate. $P<0.05$ was considered statistically significant. Statistical analysis and graphs were compiled by PRISM Mac version 6.0 (GraphPad Software, Inc., La Jolla, CA) and SAS 9.3 for Windows (Cary, NC).

\section{Results}

\section{Functional Assessment of ASO in Vitro and in Vivo}

In cultured human renal proximal tubular epithelial cells, ASO suppressed the miR-182-5p expression levels in a concentration-dependent manner 24 hours after transfection. In contrast, $\mathrm{MM}$ and saline had no effect on miR-182-5p expression level compared with untreated cells (Figure 1A).

Intravenous administration of a single ASO dose of 25 $\mathrm{mg} / \mathrm{kg}$ into mice decreased kidney miR-182-5p levels to $25 \%$ of baseline from 6 to 96 hours after injection. Even ASO doses of only $2.5 \mathrm{mg} / \mathrm{kg}$ resulted in a stable suppression of miR-182-5p after 24 hours and lasted for at least 96 hours. MM control at a concentration of $25 \mathrm{mg} / \mathrm{kg}$ did not affect renal miR-182-5p expression (Figure 1B).

\section{ASO Ameliorated Kidney Function during the Course of AKI}

miR-182-5p expression significantly increased in the injured kidney at days 2 and 7. ASO kinetics studies showed sound suppression of renal miR-182-5p at these two time points in AKI rat kidneys as also observed previously in the uninjured mouse kidneys (Figure 2A). Intravenous injection of 2.5 $\mathrm{mg} / \mathrm{kg}$ ASO resulted in a statistically better preservation of renal function. The maximum creatinine elevation was found on day 2 (ASO $25 \mathrm{mg} / \mathrm{kg}$ : median, $2.8 \mathrm{mg} / \mathrm{dL}$ [interquartile range (IQR), 0.7 to $5.0 \mathrm{mg} / \mathrm{dL}$ ]; ASO $2.5 \mathrm{mg} /$ kg: median, $1.9 \mathrm{mg} / \mathrm{dL}$ [IQR, 1.3 to $3.2 \mathrm{mg} / \mathrm{dL}$ ]; MM 25 $\mathrm{mg} / \mathrm{kg}$ : median, $5.7 \mathrm{mg} / \mathrm{dL}$ [IQR, 5.0 to $5.8 \mathrm{mg} / \mathrm{dL}$ ]; saline: median, $4.4 \mathrm{mg} / \mathrm{dL}$ [IQR, 3.5 to $5.8 \mathrm{mg} / \mathrm{dL}$ ]; $P=0.016$,

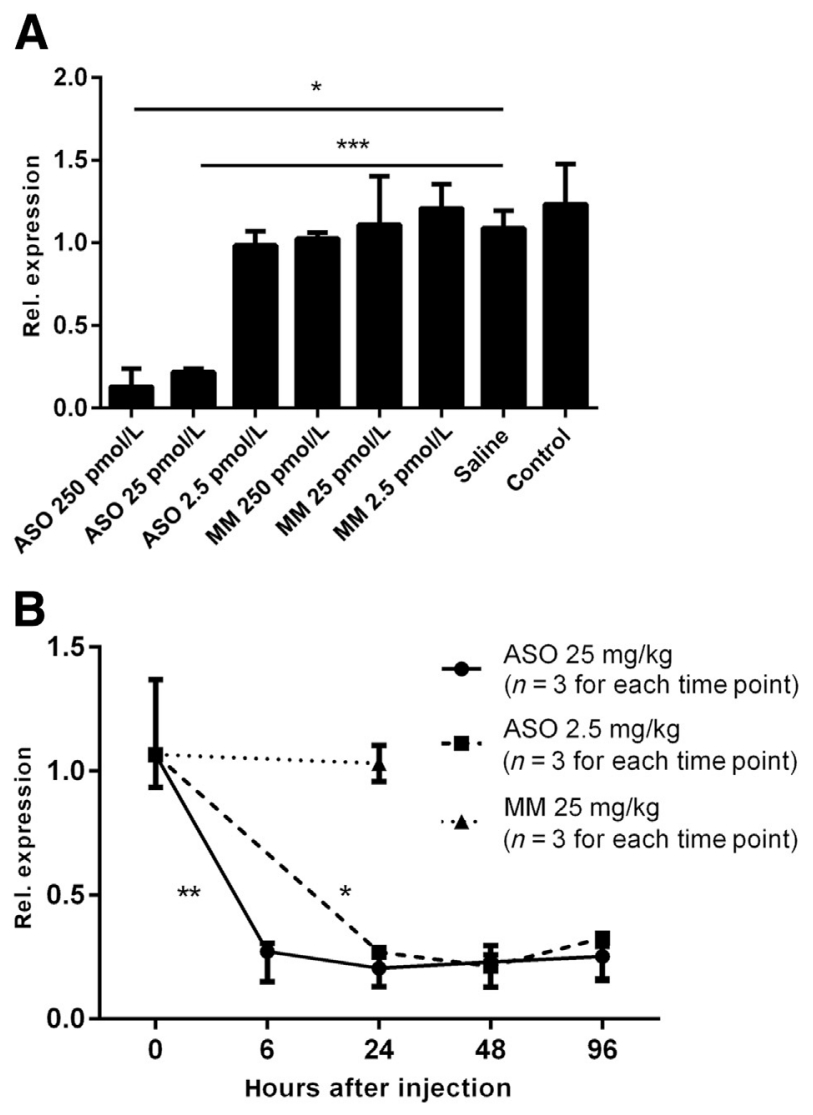

Figure 1 ASO inhibits miR-182-5p expression in vitro and in vivo. Relative expression values of miR-182-5p in HK2 cell culture and mouse kidneys determined by real-time quantitative PCR. A: miR-182-5p expression levels in HK2 cell culture 24 hours after transfection with ASO and MM $(250,25$, and $2.5 \mathrm{pmol} / \mathrm{L})$ or saline alone. Control refers to untreated cells. The differences were analyzed by $t$-test. B: miR-182-5p expression levels in kidneys of male C57BL/6 mice injected intravenously with ASO (25 and 2.5 $\mathrm{mg} / \mathrm{kg}$ body weight) and MM after $6,24,48$, and 96 hours. Saline-treated mice after 24 hours refers to baseline expression levels. Data are expressed as median and IQR. ${ }^{*} P<0.05,{ }^{*} P<0.01$, and ${ }^{* * *} P<0.001, t$-test. AS0, anti-miR-182-5p oligonucleotide; HK2, human renal proximal tubular epithelial cells; IQR, interquartile range; MM, mismatch oligonucleotide; Rel, relative.

analysis of variance; $P=0.021$ ASO $2.5 \mathrm{mg} / \mathrm{kg}$ versus saline, Dunnett test; ASO $25 \mathrm{mg} / \mathrm{kg}$ versus MM, Dunnett test; $P=0.180$ ASO $25 \mathrm{mg} / \mathrm{kg}$ versus MM, Dunnett test) (Figure 2, B and D). Accordingly, blood urea nitrogen levels were reduced in the ASO groups over the observation period as well (Figure 2, C and E). The slopes of the trajectories from day 2 onward of the saline group were significantly lower than the ASO group (Supplemental Table S1).

The 10-fold higher dose of ASO could not further ameliorate the functional damage (Figure 2, D and E). However, the creatinine levels were higher in both groups (ASO $25 \mathrm{mg} / \mathrm{kg}$ and MM) than in the ASO $2.5 \mathrm{mg} / \mathrm{kg}$ and saline groups. The explanation is that one rat in each group died due to renal failure on day 3 and 4, respectively, and the last creatinine values were included into the analysis according to protocol. Body weight and sodium and 


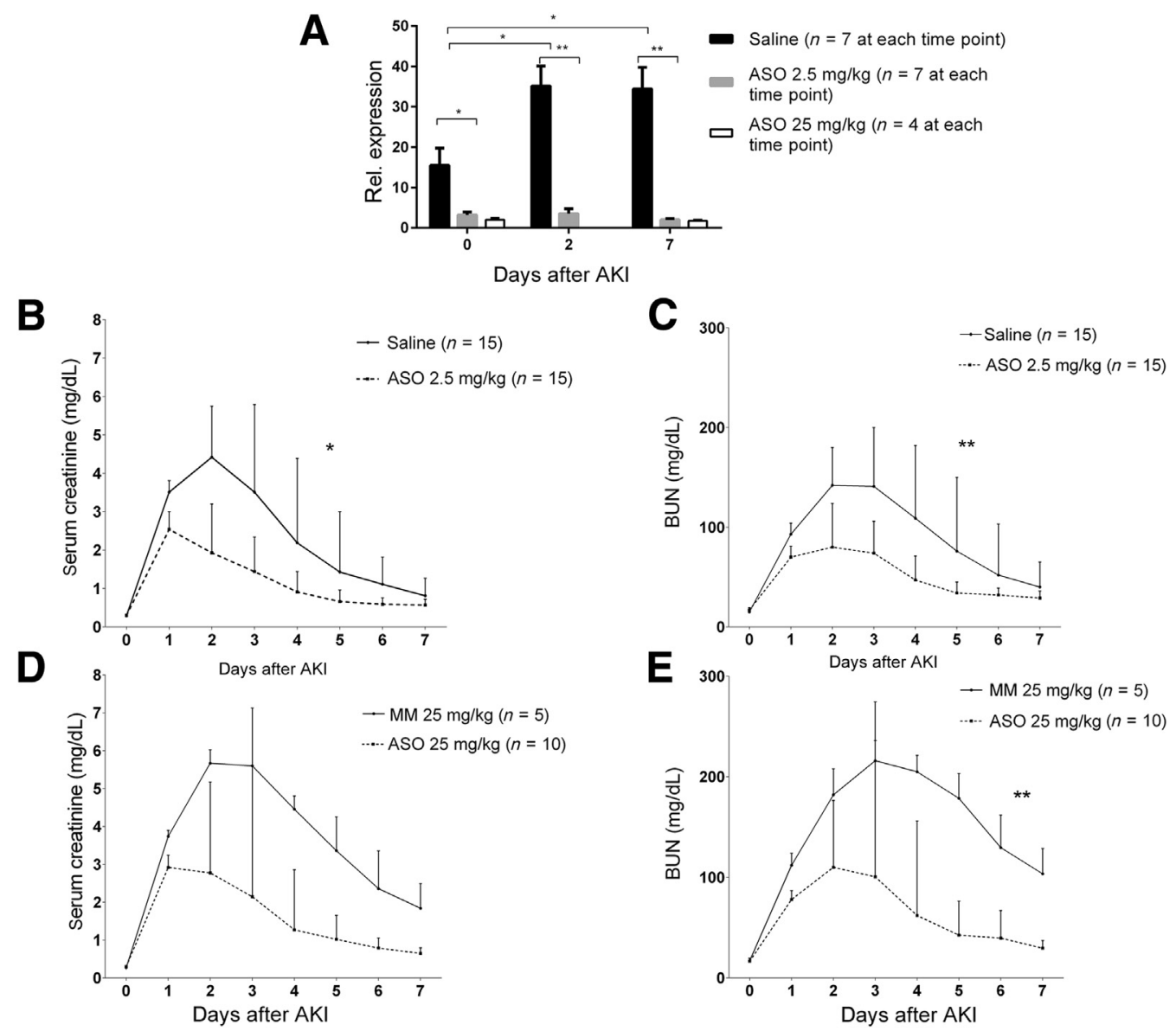

Figure 2 Efficiency of miR-182-5p inhibition and effect of ASO treatment on kidney function after AKI induction. A: miR-182-5p expression levels at day 0 (right kidney) and day 2 and 7 after ischemic reperfusion injury. miR-182-5p expression significantly increases in injured kidney without treatment at day 2 and 7. ASO treatment with a concentration of $2.5 \mathrm{mg} / \mathrm{kg}$ could successfully inhibit the expression of miR-182-5p in the kidney at day 0,2 , and 7. B and C: Serum creatinine (B) and BUN (C) levels in rats treated with ASO $(2.5 \mathrm{mg} / \mathrm{kg})$ were significantly lower than in the saline groups. D and E: Serum creatinine (D) and BUN (E) trajectories between the MM and ASO $25 \mathrm{mg} / \mathrm{kg}$ groups. The four groups are displayed in two separate graphs for better visibility. Data are expressed as median and IQR. ${ }^{*} P<0.05,{ }^{*} P<0.01$, analysis of variance of day 2 values and Dunnett post hoc test. AKI, acute kidney injury; ASO, anti-miR182-5p oligonucleotide; BUN, blood urea nitrogen; IQR, interquartile range; MM, mismatch oligonucleotide; Rel, relative.

potassium serum concentrations were similar in the treatment groups compared with the control groups (Supplemental Figure S3).

\section{Kidney Morphology Is Preserved by ASO Treatment}

Histology scores are shown for day 2 (Table 2) and day 7 (Table 3) with the corresponding $P$ values. The control group showed extensive tubular cells necrosis at day 2 compared with uninjured kidneys (Figure 3, A and B), followed by marked signs of tubular cell regeneration at day 7 (Figure 3, D and E). The pattern and severity of injury were virtually identical for animals receiving saline or MM, respectively. Treatment of animals with ASO in both concentrations resulted in significant attenuation of tubular injury, recorded semiquantitatively in overall injury score [ASO both groups: (median, 1; IQR, 1 to 1 ) versus saline (median, 3; IQR, 3 to 3) versus MM (median, 3; IQR, 3 to 3); $P<0.001$, analysis of variance]. At day 2, tubuli showed only mild-to-moderate signs of injury with ectasia, flattened epithelial cells, and some protein casts (Figure 3C). The difference among groups was even more striking at day 7 when tubular morphology returned to almost normal in animals treated with ASO $2.5 \mathrm{mg} / \mathrm{kg}$ (Figure 3, D-F).

\section{Altered Gene and Protein Expression Response through miR-182-5p Inhibition after Ischemic Reperfusion Injury}

The inhibition of miR-182-5p by ASO resulted in the altered gene expression levels of 48 genes on day 2 and 23 genes on day 7 after ischemic insult (Supplemental Figure S4). To validate functional consequences on a protein level in kidney lysates we selected two of these genes from day 2 with at least one predicted binding site for miR-182-5p and an established function in kidney injury based on the available literature: Kcnj10 and Fam129a (Niban). Performing ELISAs on the rat kidney lysates we found that Kcnj10 was up-regulated and 
Table 2 Histology Scores of Control and Treatment Groups at Day 2 and Corresponding $P$ Values, Comparing the ASO and the Control Groups

\begin{tabular}{llll}
\hline Injury & $\begin{array}{l}\text { Control group, } \\
\text { saline }\end{array}$ & $\begin{array}{l}\text { Treatment group, } \\
\text { ASO } 2.5 \mathrm{mg} / \mathrm{kg}\end{array}$ & $P$ value \\
\hline Overall injury & 2 & 1 & 0.272 \\
Vacuolization & 0 & 0 & $\mathrm{n}$ \\
Tubular ectasia & 1 & 1 & 0.495 \\
Protein casts & 2 & 1 & 0.272 \\
Luminal debris & 2 & 1.5 & 0.591 \\
Acute cell necrosis & 1 & 1 & 0.495 \\
Calcification & 0 & 0 & $\mathrm{n}$ \\
Regeneration & 0 & 0.5 & 0.789 \\
Int. inflammation & 0 & 0 & 0.495 \\
Int. fibrosis & 0 & 0 & $\mathrm{n}$ \\
\hline
\end{tabular}

Median is shown for at least three independent samples in each group. AS0, anti-miR-182-5p oligonucleotide; Int, interstitial; $n, P$ could not be computed because scores are 0 .

that Fam129a was down-regulated in the ASO group $(P=0.008)$ (Figure 4A) compared with control $(P=0.021)$ (Figure 4B) on day 2, corresponding to the results of the DNA microarray. We further tested two verified targets of miR-182$5 \mathrm{p}$ that are associated with kidney inflammation. Protein levels of CYLD and CCND2 were up-regulated in the ASOtreated mice compared with control mice at day $7(P=0.008$; Figure 4C; $P=0.016$; Figure 4D).

Performing pathway analyses in kidney samples from ASO-treated rats and untreated controls that were sampled on day 2 after $\mathrm{AKI},{ }^{21,22}$ we found an overexpression of differently regulated biological processes in the treatment group that were associated with cell proliferation and metabolism, as well as protein phosphorylation and wound healing (Supplemental Table S2). On day 7 we found an overexpression of differently regulated processes related to wound healing, tissue regeneration, and the extracellular matrix, which corresponds to the morphologic changes that were observed in the histology (Supplemental Table S2 and Figure 3, respectively).

\section{ASO Treatment of ex Vivo Machine-Perfused Pig Kidney}

miR-182-5p was strongly down-regulated by ASO treatment within 2 hours of normothermic perfusion. Although miR-182-5p was decreasing in the saline group as well, most probably due to cell apoptosis, ASO treatment induced a much stronger reduction and stayed down-regulated during the whole perfusion period. Biopsies from the salinetreated kidneys showed a stable higher level of miR-182-5p (Figure 5A). The expression of selected targets of miR-182$5 \mathrm{p}$ was changed remarkably as well (Figure 5B), corresponding with the results of the gene expression array (Supplemental Figure S4).

\section{Discussion}

miR-182-5p was found to be consistently up-regulated after ischemic insult in human kidneys and animal models.

Table 3 Histology Scores of Control and Treatment Groups at Day 7 and Corresponding $P$ Values, Comparing the ASO and the Control Groups

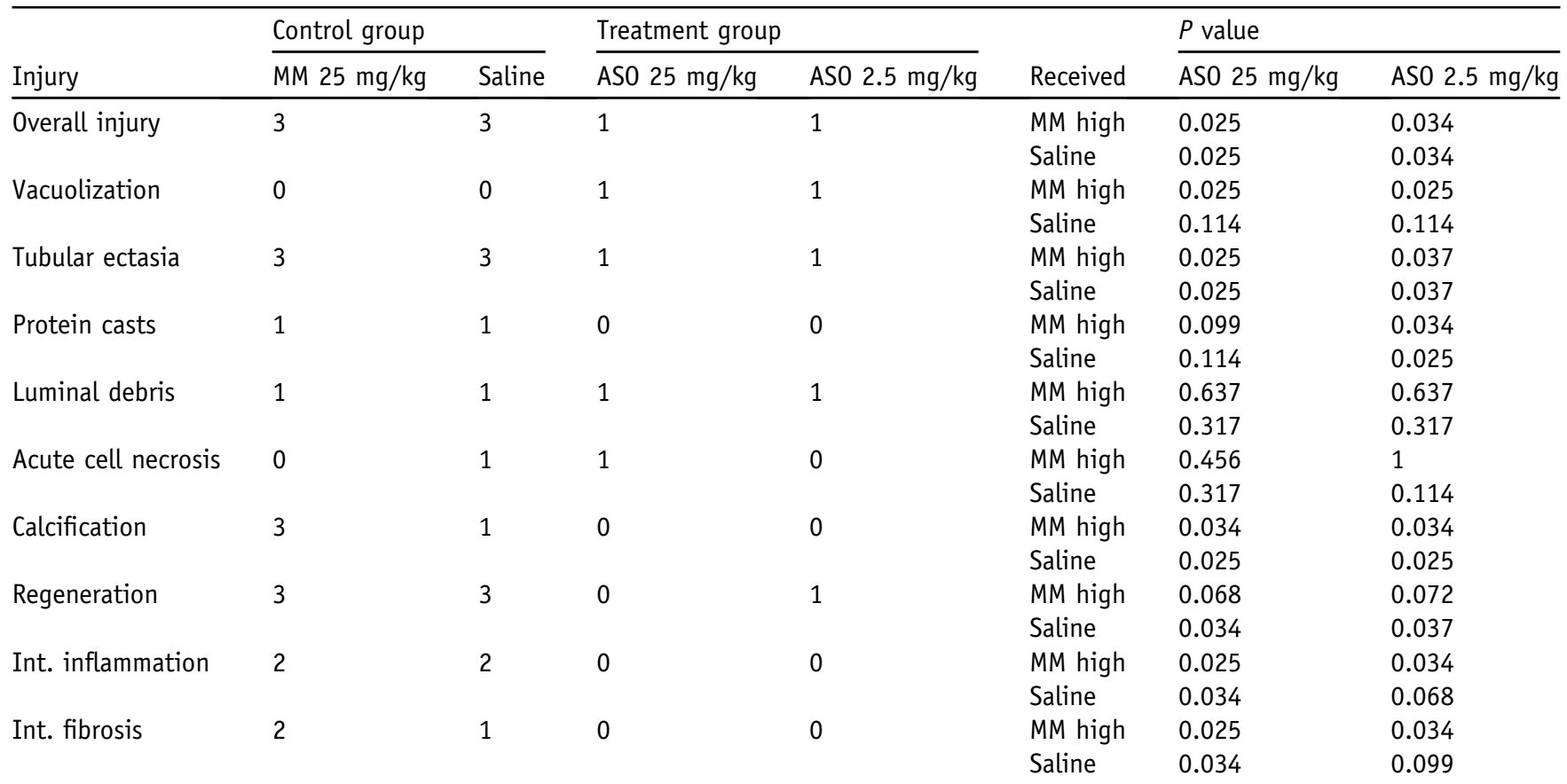

Slides were scored according to Banff07 donor kidney classification by a pathologist (H.R.) blinded for the intervention. Median is shown for at least three independent samples in each group.

AS0, anti-miR-182-5p oligonucleotide; Int, interstitial; MM, mismatch oligonucleotide. 

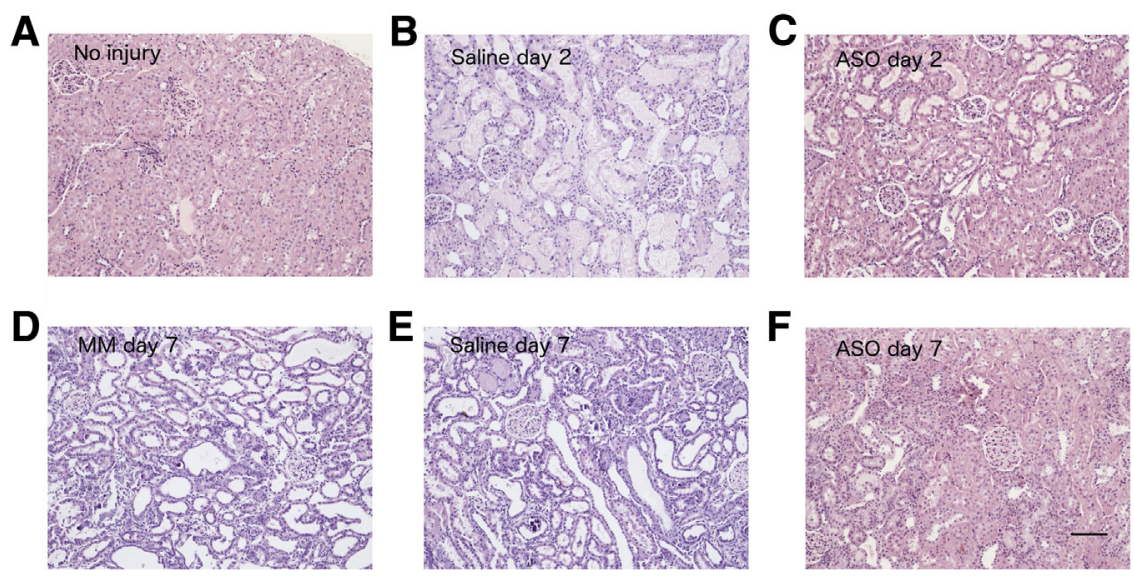

Figure 3 Representative sections from the kidney biopsies. A: Normal control kidney (without ischemic injury). B and C: Ischemic injury at day 2 with saline treatment showing widespread acute tubular necrosis (B) or treated with ASO $2.5 \mathrm{mg} / \mathrm{kg}$ showing mild injury with tubular ectasia but without tubular cell necrosis (C). D-F: At day 7 animals receiving $M M \quad 2.5 \mathrm{mg} / \mathrm{kg}$ (D) or saline (E) showed extensive tubular injury (high-grade ectasia, calcification) and significant signs of tubular cell regeneration, whereas treatment with ASO resulted in almost normal histology with only very mild signs of tubular injury and cellular regeneration (F). Scale bar $=100 \mu \mathrm{m}$. ASO, antimiR-182-5p oligonucleotide; MM, mismatch oligonucleotide.
Particularly, renal miR-182-5p was significantly increased in post-transplantation AKI patients and showed statistical correlations with global gene expression changes during the development of AKI. ${ }^{8}$ The data of the present study demonstrate that selective in vivo inhibition of miR-182-5p in an ischemic reperfusion injury model improved kidney function significantly during the time course of 7 days after insult. Furthermore, miR-182-5p antisense-treated kidneys show improved histology and less fibrosis on day 7 after ischemic reperfusion injury.

After gene expression analysis, we performed ELISAs to validate the gene expression on protein level. From the microarray data we selected two targets that were deregulated after ASO treatment which had at least one predicted binding site for miR-182-5p, based on three independent prediction algorithms (see Materials and Methods) and were associated with kidney injury in a literature research: $\mathrm{Kcnj} 10$ is a pH-sensitive $\mathrm{K}^{+}$channel and mRNA levels are decreased after ischemia/reperfusion injury. ${ }^{23}$ In our study miR-182-5p inhibition by ASO up-regulated Kcnj10 on both a gene expression as well as protein level. Fam129a (Niban) gene is associated with fibrosis in obstructive nephropathy $^{24}$ and was down-regulated by ASO treatment.

We further evaluated changes in the protein level of two verified targets of miR-182-5p. CYLD plays a protective role in tubulointerstitial inflammation in IgA nephropathy by a presumed regulation of the peroxisome proliferatoractivated receptor $\gamma$ pathway and is crucial for maintenance
A

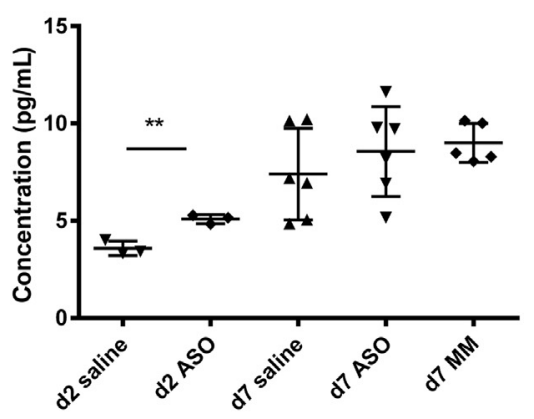

C

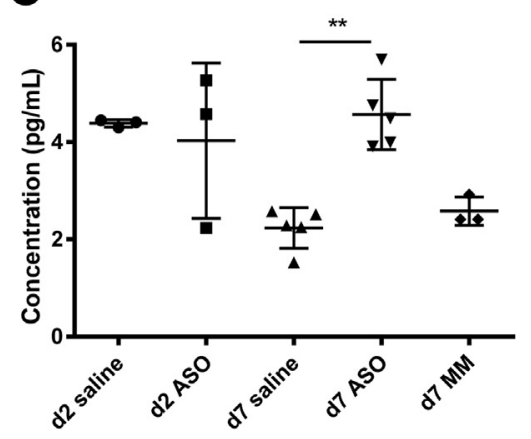

B

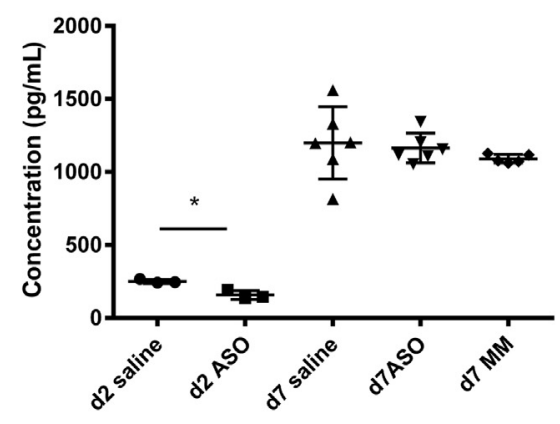

D

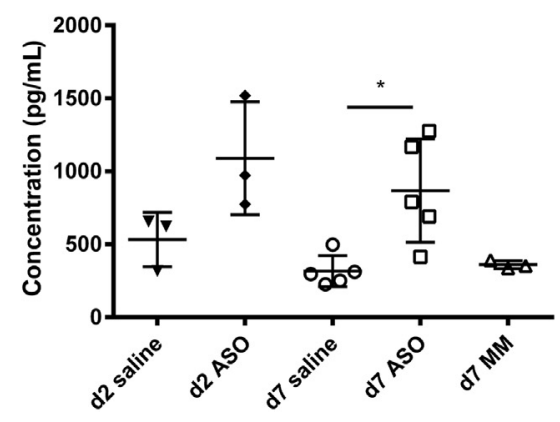

Figure 4 Protein level of different predicted or validated miR-182-5p targets determined by ELISA at day 2 and 7 after ischemic injury. A-D: Kcnj10 protein levels were up-regulated by inhibition of miR-182-5p after ischemia (A), Fam129a levels are lowered by the ASO treatment (B), and CYLD (C) and CCND2 (D), two validated targets of miR-182-5p, are up-regulated on miR-182-5p inhibition by ASO. Data are expressed as means \pm SD. $n=3$ at day $2 ; n=5$ at day $7 .{ }^{*} P<0.05,{ }^{*} P<0.01$, derived from $t$-test. ASO; antisense oligonucleotide treatment; CCND2, cyclin D2; CYLD, cylindromatosis; d2, day 2; d7, day 7; ELISA, enzyme-linked immunosorbent assay; MM, mismatch oligonucleotide; saline, saline treatment before ischemia. 

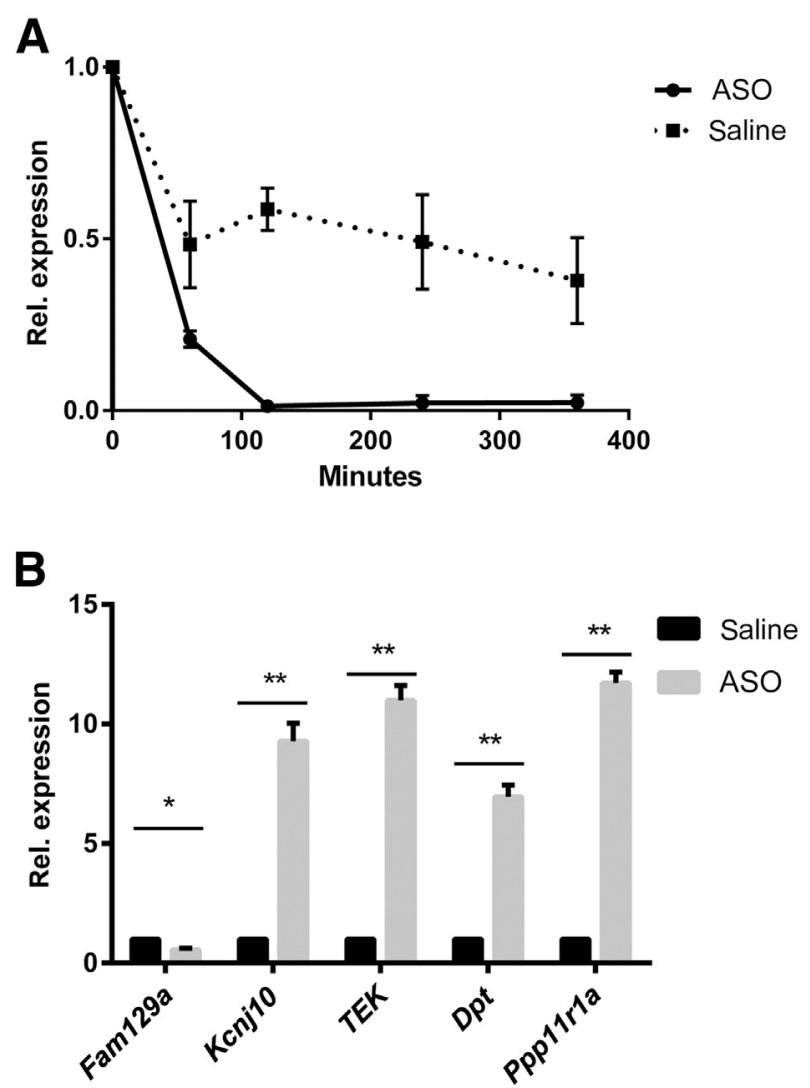

Figure 5 ASO treatment efficacy during ex vivo normothermic machine perfusion with UW solution of a pig kidney. A: miR-182-5p expression levels before ASO treatment (0 hour) and after 2, 4, and 6 hours. miR-182-5p expression decreased in the kidney treated with $25 \mathrm{mg}$ of ASO. B: Expression ratios of various miR-182-5p targets after ASO treatment, compared with saline-treated pig kidney. Data are expressed as median and SD of triplicates. $n=3$ for all groups. ${ }^{*} P<0.05,{ }^{*} P<0.01$. AS0, anti-miR-182-5p oligonucleotide; Rel, relative; UW, University of Wisconsin.

of renal function. ${ }^{25}$ Expression as well as translation of CYLD was up-regulated after ASO treatment. CCND2 plays role in renal cell cycle and in the progression of diabetic nephropathy. ${ }^{26,27}$

Lee et $\mathrm{al}^{28}$ showed in a model of natural tolerance to ischemia that miR-182-5p was profoundly depressed, thereby resulting in protective effects against oxygen/glucose deprivation-induced cell death. Furthermore, miR-182-5p reduced the expression of the anti-apoptotic proteins BclII and cell-cycle regulatory cyclin-dependent kinase inhibitors such as p21 and thereby inhibiting cell regeneration. ${ }^{29}$ Ectopic overexpression of miR-182-5p induced apoptosis and cell-cycle arrest in epithelial cells ${ }^{30}$ and targets a network of genes in DNA repair. ${ }^{31,32}$ In addition, miR-182-5p integrates apoptosis, growth, and differentiation of glioblastoma in vitro and in vivo. ${ }^{33}$ These data are in accordance with our study showing that miR-182-5p regulates kidney parenchyma survival in vivo and that miR-182-5p expression is associated with adverse kidney function in humans and in animal models.
By their ability of regulating a wide variety of downstream events, controlling the level of miRNAs has a great potential. ${ }^{7}$ Indeed, both mimicking and attenuating the in vivo effect of miRNAs is feasible and applicable in the clinic. $^{7,34,35}$ Furthermore, the kidney is an especially attractive target because single-stranded oligonucleotides mostly end up in the kidney. ${ }^{36}$ Similar to our study, inhibition of miR-24 by systemic administration of ASOs in mice before ischemia reperfusion injury resulted in a significant improvement in survival and kidney function with a reduction of apoptosis. ${ }^{37}$

Molitoris et $\mathrm{al}^{38}$ targeted $p 53$ a pivotal protein in the apoptotic pathway with ASO and successfully decreased the cellular transcript and thereby attenuated the p53-mediated apoptosis by siRNA in both cortical and corticomedullary regions. The oligonucleotides rapidly reached the kidney after systemic administration, and the attenuation was time and dose dependent. Singaravelu and Padanilam ${ }^{39}$ reported similar data previously, targeting Siva, a downstream effector of p53 in acute kidney injury. Inhibition of Siva by ASO resulted in functional and morphologic protection from injury and prevented apoptosis.

Other researchers used a reversed approach to alleviate AKI in experimental rat models. Bijkerk et $\mathrm{al}^{40}$ showed that a functioning renal peritubular capillary network is the important limiting factor in the recovery from ischemic injury. miR-126 facilitated vascular regeneration by functioning as an angiomiR and by modulating mobilization of hematopoietic stem/progenitor cells. In a model of cisplatininduced AKI, antagonism of miR-34a with a prophylactic treatment of specific ASOs increased cell death in the kidney during cisplatin treatment; therefore, miR-34a may play a cytoprotective role for cell survival. ${ }^{41}$

To test the feasibility of miR-182-5p inhibition ex vivo in renal allografts, we built a normothermic machine perfusion system. This approach was used to retain injected oligonucleotides to the kidney, thereby preventing side effects in other organ systems and reducing the total amount of antisense needed. We successfully demonstrated the feasibility of antisense technology against miRNA targets.

There are, however, intrinsic limitations to experimental animal studies. Certainly, AKI in rats does not perfectly mirror the human AKI setting whereby many more parameters than ischemia usually contribute to injury at the same time. Furthermore, localization of ASO was not thoroughly tested because our main goal was to prove efficacy. We used an ex vivo-perfused pig kidney model that closely resembles the human allograft setting and showed ASO effectiveness.

Our findings may have the potential to change the practice of human kidney transplantation whereby AKI is inevitable and roughly $25 \%$ of all deceased donor transplant recipients experienced delayed allograft function. This devastating condition, which is the strongest risk factor for reduced graft longevity, may now be successfully tackled by using antisense technology against the miR-182-5p target. 


\section{Acknowledgments}

We thank Markus Jeitler and Martin Bilban for hybridization, washing, and scanning the Affymetrix GeneChip Rat Gene 2.0 ST arrays (Core Facility Genomics, Core Facilities, Medical University of Vienna). We also thank Johann Horvat and Thomas Schlöglhofer for technical assistance.

\section{Supplemental Data}

Supplemental material for this article can be found at http://dx.doi.org/10.1016/j.ajpath.2016.09.011.

\section{References}

1. Heinze G, Collins S, Benedict MA, Nguyen LL, Kramar R, Winkelmayer WC, Haas M, Kainz A, Oberbauer R: The association between angiotensin converting enzyme inhibitor or angiotensin receptor blocker use during postischemic acute transplant failure and renal allograft survival. Transplantation 2006, 82:1441-1448

2. Hauser P, Schwarz C, Mitterbauer C, Regele HM, Muhlbacher F, Mayer G, Perco P, Mayer B, Meyer TW, Oberbauer R: Genome-wide gene-expression patterns of donor kidney biopsies distinguish primary allograft function. Lab Invest 2004, 84:353-361

3. Kainz A, Wilflingseder J, Mitterbauer C, Haller M, Burghuber C, Perco P, Langer RM, Heinze G, Oberbauer R: Steroid pretreatment of organ donors to prevent postischemic renal allograft failure: a randomized, controlled trial. Ann Intern Med 2010, 153:222-230

4. Wilflingseder J, Kainz A, Muhlberger I, Perco P, Langer R, Kristo I, Mayer B, Oberbauer R: Impaired metabolism in donor kidney grafts after steroid pretreatment. Transpl Int 2010, 23:796-804

5. Wilflingseder J, Regele H, Perco P, Kainz A, Soleiman A, Muhlbacher F, Mayer B, Oberbauer R: miRNA profiling discriminates types of rejection and injury in human renal allografts. Transplantation 2013, 95:835-841

6. El Sabbahy M, Vaidya VS: Ischemic kidney injury and mechanisms of tissue repair. Wiley Interdiscip Rev Syst Biol Med 2011, 3:606-618

7. Janssen HL, Reesink HW, Lawitz EJ, Zeuzem S, Rodriguez-Torres M Patel K, van der Meer AJ, Patick AK, Chen A, Zhou Y, Persson R, King BD, Kauppinen S, Levin AA, Hodges MR: Treatment of HCV infection by targeting microRNA. N Engl J Med 2013, 368:1685-1694

8. Wilflingseder J, Sunzenauer J, Toronyi E, Heinzel A, Kainz A, Mayer B, Perco P, Telkes G, Langer RM, Oberbauer R: Molecular pathogenesis of post-transplant acute kidney injury: assessment of whole-genome mRNA and miRNA profiles. PLoS One 2014, 9:e104164

9. Oberbauer R, Rohrmoser M, Regele H, Muhlbacher F, Mayer G: Apoptosis of tubular epithelial cells in donor kidney biopsies predicts early renal allograft function. J Am Soc Nephrol 1999, 10:2006-2013

10. Schwarz C, Regele H, Steininger R, Hansmann C, Mayer G, Oberbauer R: The contribution of adhesion molecule expression in donor kidney biopsies to early allograft dysfunction. Transplantation 2001, 71:1666-1670

11. Oberbauer R, Schwarz C, Regele HM, Hansmann C, Meyer TW, Mayer G: Regulation of renal tubular cell apoptosis and proliferation after ischemic injury to a solitary kidney. J Lab Clin Med 2001, 138: 343-351

12. Stittrich AB, Haftmann C, Sgouroudis E, Kuhl AA, Hegazy AN, Panse I, Riedel R, Flossdorf M, Dong J, Fuhrmann F, Heinz GA, Fang Z, Li N, Bissels U, Hatam F, Jahn A, Hammoud B, Matz M, Schulze FM, Baumgrass R, Bosio A, Mollenkopf HJ, Grun J, Thiel A, Chen W, Hofer T, Loddenkemper C, Lohning M, Chang HD, Rajewsky N, Radbruch A, Mashreghi MF: The microRNA miR-182 is induced by IL-2 and promotes clonal expansion of activated helper T lymphocytes. Nat Immunol 2010, 11:1057-1062

13. Solez K, Colvin RB, Racusen LC, Haas M, Sis B, Mengel M, Halloran PF, Baldwin W, Banfi G, Collins AB, Cosio F, David DS, Drachenberg C, Einecke G, Fogo AB, Gibson IW, Glotz D, Iskandar SS, Kraus E, Lerut E, Mannon RB, Mihatsch M, Nankivell BJ, Nickeleit V, Papadimitriou JC, Randhawa P, Regele H, Renaudin K, Roberts I, Seron D, Smith RN, Valente M: Banff 07 classification of renal allograft pathology: updates and future directions. Am J Transplant 2008, 8:753-760

14. Gentleman R, Carey V, Huber W, Irizarry R, Dudoit S: Bioinformatics and Computational Biology Solutions Using R Bioconductor. New York, NY, Springer Publications, 2005

15. Irizarry RA, Bolstad BM, Collin F, Cope LM, Hobbs B, Speed TP: Summaries of Affymetrix GeneChip probe level data. Nucleic Acids Res 2003, 31:e15

16. Paraskevopoulou MD, Georgakilas G, Kostoulas N, Vlachos IS, Vergoulis T, Reczko M, Filippidis C, Dalamagas T, Hatzigeorgiou AG: DIANA-microT web server v5.0: service integration into miRNA functional analysis workflows. Nucleic Acids Res 2013, 41:W169-W173

17. Reczko M, Maragkakis M, Alexiou P, Grosse I, Hatzigeorgiou AG: Functional microRNA targets in protein coding sequences. Bioinformatics 2012, 28:771-776

18. Enright AJ, John B, Gaul U, Tuschl T, Sander C, Marks DS: MicroRNA targets in Drosophila. Genome Biol 2003, 5:R1

19. Friedman RC, Farh KK, Burge CB, Bartel DP: Most mammalian mRNAs are conserved targets of microRNAs. Genome Res 2009, 19: 92-105

20. Chou CH, Chang NW, Shrestha S, Hsu SD, Lin YL, Lee WH, Yang CD, Hong HC, Wei TY, Tu SJ, Tsai TR, Ho SY, Jian TY, Wu HY, Chen PR, Lin NC, Huang HT, Yang TL, Pai CY, Tai CS, Chen WL, Huang CY, Liu CC, Weng SL, Liao KW, Hsu WL, Huang HD: miRTarBase 2016: updates to the experimentally validated miRNA-target interactions database. Nucleic Acids Res 2016, 44:D239-D247

21. Huang da W, Sherman BT, Lempicki RA: Systematic and integrative analysis of large gene lists using DAVID bioinformatics resources. Nat Protoc 2009, 4:44-57

22. Huang da W, Sherman BT, Lempicki RA: Bioinformatics enrichment tools: paths toward the comprehensive functional analysis of large gene lists. Nucleic Acids Res 2009, 37:1-13

23. Garcia MA, Meca R, Leite D, Boim MA: Effect of renal ischemia/reperfusion on gene expression of a $\mathrm{pH}$-sensitive $\mathrm{K}+$ channel. Nephron Physiol 2007, 106:p1-p7

24. Liu J, Qin J, Mei W, Zhang H, Yuan Q, Peng Z, Luo R, Yuan X, Huang L, Tao L: Expression of Niban in renal interstitial fibrosis. Nephrology (Carlton) 2014, 19:479-489

25. Zhao Y, Zhang Y, Song HB, Wu F, Wang XL, Sun SC, Cui TX, Tang DQ: Proteomic analysis revealed the altered kidney protein profile of a Cyld knockout mouse model. Genet Mol Res 2015, 14:5970-5978

26. Ye W, Zhang L: Heme controls the expression of cell cycle regulators and cell growth in HeLa cells. Biochem Biophys Res Commun 2004 315:546-554

27. Suzuki H, Kato I, Usui I, Takasaki I, Tabuchi Y, Oya T, Tsuneyama K, Kawaguchi H, Hiraga K, Takasawa S, Okamoto H, Tobe K, Sasahara M: Characterization of diabetic nephropathy in CaM kinase IIalpha (Thr286Asp) transgenic mice. Biochem Biophys Res Commun 2009, 379:38-42

28. Lee YJ, Johnson KR, Hallenbeck JM: Global protein conjugation by ubiquitin-like-modifiers during ischemic stress is regulated by microRNAs and confers robust tolerance to ischemia. PLoS One 2012, 7: e47787

29. Peng X, Li W, Yuan L, Mehta RG, Kopelovich L, McCormick DL: Inhibition of proliferation and induction of autophagy by atorvastatin in PC3 prostate cancer cells correlate with downregulation of $\mathrm{Bcl} 2$ and upregulation of miR-182 and p21. PLoS One 2013, 8:e70442 
30. Rihani A, Van Goethem A, Ongenaert M, De Brouwer S, Volders PJ, Agarwal S, De Preter K, Mestdagh P, Shohet J, Speleman F, Vandesompele J, Van Maerken T: Genome wide expression profiling of p53 regulated miRNAs in neuroblastoma. Sci Rep 2015, 5:9027

31. Kabacik S, Manning G, Raffy C, Bouffler S, Badie C: Time, dose and ataxia telangiectasia mutated (ATM) status dependency of coding and noncoding RNA expression after ionizing radiation exposure. Radiat Res 2015, 183:325-337

32. Krishnan K, Steptoe AL, Martin HC, Wani S, Nones K, Waddell N, Mariasegaram M, Simpson PT, Lakhani SR, Gabrielli B, Vlassov A, Cloonan N, Grimmond SM: MicroRNA-182-5p targets a network of genes involved in DNA repair. RNA 2013, 19:230-242

33. Kouri FM, Hurley LA, Daniel WL, Day ES, Hua Y, Hao L, Peng CY, Merkel TJ, Queisser MA, Ritner C, Zhang H, James CD, Sznajder JI, Chin L, Giljohann DA, Kessler JA, Peter ME, Mirkin CA, Stegh AH: miR-182 integrates apoptosis, growth, and differentiation programs in glioblastoma. Genes Dev 2015, 29:732-745

34. Stenvang J, Petri A, Lindow M, Obad S, Kauppinen S: Inhibition of microRNA function by antimiR oligonucleotides. Silence 2012, 3:1

35. Bader AG, Brown D, Winkler M: The promise of microRNA replacement therapy. Cancer Res 2010, 70:7027-7030

36. Oberbauer R, Schreiner GF, Biber J, Murer H, Meyer TW: In vivo suppression of the renal $\mathrm{Na}+/ \mathrm{Pi}$ cotransporter by antisense oligonucleotides. Proc Natl Acad Sci U S A 1996, 93:4903-4906
37. Lorenzen JM, Kaucsar T, Schauerte C, Schmitt R, Rong S, Hubner A, Scherf K, Fiedler J, Martino F, Kumarswamy R, Kolling M, Sorensen I, Hinz H, Heineke J, van Rooij E, Haller H, Thum T: MicroRNA-24 antagonism prevents renal ischemia reperfusion injury. J Am Soc Nephrol 2014, 25:2717-2729

38. Molitoris BA, Dagher PC, Sandoval RM, Campos SB, Ashush H, Fridman E, Brafman A, Faerman A, Atkinson SJ, Thompson JD, Kalinski H, Skaliter R, Erlich S, Feinstein E: siRNA targeted to p53 attenuates ischemic and cisplatin-induced acute kidney injury. J Am Soc Nephrol 2009, 20:1754-1764

39. Singaravelu K, Padanilam BJ: p53 target Siva regulates apoptosis in ischemic kidneys. Am J Physiol Renal Physiol 2011, 300: F1130-F1141

40. Bijkerk R, van Solingen C, de Boer HC, van der Pol P, de Bruin RG, van Oeveren-Rietdijk AM, Lievers E, Schlagwein N, van Gijlswijk DJ, Roeten MK, Neshati Z, de Vries AA, Rodijk M, PikeOverzet K, van den Berg YW, van der Veer EP, Versteeg HH, Reinders ME, Staal FJ, van Kooten C, Rabelink TJ, van Zonneveld AJ: Hematopoietic microRNA-126 protects against renal ischemia/reperfusion injury by promoting vascular integrity. J Am Soc Nephrol 2014, 25:1710-1722

41. Bhatt K, Zhou L, Mi QS, Huang S, She JX, Dong Z: MicroRNA-34a is induced via p53 during cisplatin nephrotoxicity and contributes to cell survival. Mol Med 2010, 16:409-416 